\title{
THE IMPACT OF ICT ON THE WORK OF THE SCHOOL PRINCIPAL
}

\author{
Margaret Haughey \\ University of Alberta, Canada
}

Abstract: Principals' work has been affected through the use of information and communication technology (ICT): management information systems have regularized, enforced, and revealed inconsistencies that need to be addressed; e-mail has increased and intensified interactions and expectations within the school and with central administration. ICT have given teachers more information about students but they have also made teaching more transparent and accessible. Similarly, the principals' work is more visible to central administrators. As principals and teachers become more comfortable and competent in using ICT it is likely they will develop school-wide instructional as well as administrative responses to ICT.

Key words: Information and communication technology, management information systems, principal's work

Much of the work on information and communication technology (ICT) in schools has focused on the teacher's in-class use of ICT in instruction but ICT have also influenced the work of the principal. Despite this, few studies have examined the impact of information and communications technologies on the work of the school principal. This paper reports on the research available and the findings of one such study. Technology is process and product, figure and ground. It is not neutral, despite our definition of it as a tool, which by implication, we can control. Instead, it is a set of practices that shape us even as we shape them. Its use as a set of management practices shaping administrative work and the work of the school is the focus of this paper.

What do we demand of principals in terms of technology? First, not only has the landscape of principalship increasingly stressed the requirement that principals are key leaders in self-managed schools (Caldwell \& Spinks,

The original version of this chapter was revised: The copyright line was incorrect. This has been corrected. The Erratum to this chapter is available at DOI: 10.1007/978-0-387-35689-1_19 
1992), but information communications technologies (ICT) have become part of that work. Initially, the pressure on principals was to know the language of computers, from bytes and gigabytes, to RAM and ROM, and in particular, to know what the software and hardware options were in ordering equipment for their schools. Stand-alone computers were followed by local area (LANs) networks. Internet access and privacy issues were to the fore. Teachers in my local jurisdiction were told in September 1999 that their end of term student report cards would be computerized. Principals handled the situation in different ways: one had a consultant come out and demonstrate how to access, fill in, and print individual report cards. Another put a computer in the staff room and told the staff they should all have played one game of solitaire on it by November. The first approach raised the level of anxiety of the teachers; provided with one in-service, they were expected to be able to emulate the consultant. Teachers at the other school, laughed, joked and helped each other as they learned to play, discovering in the process not only to use a computer but also how to calculate percentages, and to complete the report cards.

\section{COMMUNICATIONS TECHNOLOGIES}

The introduction of computers into schools might seem to have a greater impact on teachers than administrators but that is not the case. Today's principals are expected to be familiar with computing technologies, to be able to create spreadsheets and to file forms with the central office, to use email and send attachments, to do their own inputting, and often to be comfortable using digital cameras and graphics programs to create suitable memos.

This is not an area of extensive research. In one study, Gurr (2001) interviewed 20 principals in one Australian state about the impact of ICT on their workload. The principals noted the expectations for spreadsheets, email and word-processing, and they also identified various software management systems increasingly used to do budgeting and planning. Such database systems are usually loaded on the jurisdiction's server so that personnel can retrieve information about school statistics or access accounting, budgeting and reporting systems at any time. Most jurisdictions now use management information systems (MIS) to which all schools are connected. This means that data are no longer entered more than once and that sophisticated programming can provide information about individual schools and cross-school comparisons. The system collects more data and provides charts and summary sheets that in turn can influence how the school and its community are viewed. In smaller jurisdictions, principals 
have less technical support in learning how to operate these systems and such systems are less likely to be tailored to the needs of the district to quite the same degree as in larger districts. Furthermore, principals need to be able to interpret these charts and summaries and understand their relationship to the raw data.

One of the advantages of ICT is its asynchronicity. Principals in Gurr's study talked about the advantage of being able to do school work at home in the evening rather than staying in the building. During the day, principals were often so busy dealing with office visitors, handling student issues, visiting classrooms, and touring halls, that they could not spare long periods of time to do any specialized work. Many principals have told me that they now feel released from the tyranny of the telephone. They no longer have to start phoning and leaving messages for colleagues and central staff immediately they arrive in the morning so that they can receive calls from them midmorning, and hopefully be in the office to receive them. Now they email whenever they can, and can pick up the message when they have a moment. Another side effect of the use of e-mails is that relationships among principals, usually established through informal breakfast meetings, remain important and even intensify since these people are likely to be their most immediate source of information.

Many of the principals whom Gurr interviewed were already comfortable with email and Internet searching. They now did their searching for different ideas online, through targeted searches or through seeking advice from colleagues through professional listservs, whether by jurisdiction, or state or at a national or international level. Once, a principal would have telephoned a colleague about new initiatives or an academic about background research in a particular area--today's principals are going on-line for information. It is not their only source but it is becoming an important one.

Another area where principals are expected to show their competencies in handling communications technologies is in the use of presentation software. It is one obvious way of modelling comfort with technology use (and patience in the face of the inevitable failures) to teachers, students and parents. They are expected to show leadership in helping teachers teach through technology but many were not yet adequately prepared to combine information technologies with good pedagogy (Haughey 2002). Even word processing can radically change not only how principals accomplish work but also how they think and compose text (Gurr 2001). The importance of principals seeing technology as more than "wiring and workstations" was also raised by Valenza (1999), who interviewed several principals and teachers who were using technology effectively. "They saw themselves as learners," she noted. They described their management styles with words 
such as "thoughtful," "participatory," and "collaborative." All spoke of "we", of the team, of the culture of the school. All recognized the talents of their staff. They continued to look for ways to help teachers teach and to improve the learning environment. They acknowledged the acuteness of the learning curve but believed that it need not be attempted alone. How school cultures are affected is worthy of further research.

\section{MANAGEMENT INFORMATION SYSTEMS}

Today's school information systems are increasingly sophisticated. For Bober (2001) such systems provide "easy access to timely information that has relevance and purpose with the intention of empowering its users" (Italics in original). Such information management systems involve

"managing a school or district's key functional data including, but not

limited to, enrolment, student and staff demographics, course enrolments, class schedules, attendance, disciplinary actions, special programs, grades, standardized assessments, and health information" (p.2).

In a review of school information systems and their effects on school operations and culture, Bober (2001) noted that administrators have moved from student information to tracking changes in the information; from keeping academic information on each student by school to developing and maintaining a profile on the student's academic career; and from using the data to make separate fiscal or academic decisions to using databases that integrate various facets of school life.

Telem $(1996,1999)$ has completed a series of studies examining the impact of management information systems on the life of schools. In a yearlong study (1996) involving observation and in-depth interviewing, he noted that implementation of the MIS brought consistency to addressing decisionmaking areas, there was more interaction among school staff and autonomy was lessened, teachers were both more competitive and interacted and cooperated more on instructional issues, and the MIS brought a business orientation to school affairs. His 1999 study confirmed these findings and further documented the bi-directional nature of communication and accountability; teachers were held to be more accountable, but they expected to have more information about what was going on. Potential policies and procedures were disseminated more widely and rapidly and issues and concerns were addressed more promptly. He found that firmer student standards were enacted and they were applied more uniformly. Department heads and teachers interacted more frequently but heads were reluctant to give each other unsolicited advice. In a subsequent study, (1997) Telem 
focused on the new role of the school computer administrator. In large high schools, a site technologist is often hired to deal specifically with the network and its applications. As a result, the person often had a central role in administrative matters, marking unusual data, and checking to see if these were followed up. I am not sure that this would be accurate for all schools but it does alert us to implications of this new role.

It also raises questions about the impact of changing communication and information flows in school systems. Superintendents commonly use e-mail and listservs to share information with schools. Once school-based data are available, central administrators tend to use information based on system level analyses in reports, and are increasingly required to do so as government ministries turn to computerized information flows to monitor the work of school systems. Such information is both more standardized and more available across the system. Its visibility in turn puts pressures on the school to ensure that the data reflect well on the work of the school and the academic achievements of the students. Its availability changes the way decisions are made from single issues to sets of decisions, some managerial and some strategic. There is more emphasis on long-term planning since comparative data can be generated as proxy measures of progress (Bober 2001).

Yeagley (2001) reported on the use of a district management information system in his small "low-wealth" district of approximately 4,500 students. He identified four principles that guided his efforts: instructional change, staff training, communicating results and inviting feedback. He commented that instructional change was his first priority and he wanted to transform data into information that staff could use to improve student learning. While the district had already done analyses of state and national assessments, and looked at individual student results and district averages to identify patterns, it lacked sufficient data for detailed analyses. By integrating data from a variety of sources, the MIS now allowed hidden patterns to emerge.

Regardless of country, much of the initial pressure for MIS has come from the pressures for documented improvement in students' academic scores. Originating in requirements about test scores, districts found that the presence of a compilation of yearly and even semester scores allowed them to use regression analysis and other techniques to identify discrepancies between actual and predicted outcomes. The information also provided teachers with better assessment data since they saw student data across a number of subjects and not just for their own course. The emphasis was on the students' performance and often resulted in more teacher cooperation and team planning to address students' needs. The system also provided teachers with better data for self-monitoring, hence the increased competition referred to earlier. Such systems are not neutral: the 
information they provide can be used to stereotype students, reduce teachers' autonomy in instructional decisions, and sustain particular agendas such as the use of state-wide or national testing.

Other researchers have examined the implementation of management information systems in schools in Hong Kong, the Netherlands, and in England (Fung \& Visscher 2001; Visscher, Wild \& Fung 2001). In each case, the researchers identified varied levels of use in the schools. The most commonly used module was for student records.

The extent of use of management information systems is not yet ubiquitous. Most school jurisdictions have some form of computerized datacollection and retrieval but it is often confined to the information required for annual government reports. Many large schools, especially those built in the last decade, have their own school information systems to monitor and assist the information flow. It is likely that many schools have electronic reporting systems, post daily bulletins, and that staff use ICT to organize activities. However, much of this information remains anecdotal.

\section{A LOCAL CASE}

To document how ICT has changed the work of administrators, I have begun working with 10 principals and central staff in an urban school jurisdiction. The principals were chosen to reflect a range of contexts and personal interest in ICT integration. Each audio taped interview lasted approximately an hour. I used a combination of content analysis to identify general categories and then close reading to explore these topics in more detail. The description of the study findings was returned to the principals for verification and will form the basis for future annual interviews and more detailed data gathering in the next three years.

This urban jurisdiction employs about 1700 teachers and serves about 32,000 students. It has an integrated technology platform that links all 85 schools; many of those schools have local area networks, and many teachers in these schools have access to a networked computer in their classrooms. However, since the district platform is neither stable nor complete, this jurisdiction can be said to be in the beginning stages of technology integration. The district recognizes the importance of networked technology and has instituted a minimum technology standards requirement for newly appointed principals. This involves about $\mathbf{3 0}$ hours of instruction over a four-month period. The focus is on software applications and the major tools and electronic forms have been compiled into an electronic workbook with additional resource sources such as government web sites. The 
expectation is that these principals will use all the applications in their workbook in obtaining the relevant data required for central office purposes.

The workbook is a management information system and building the workbook has occurred over several years. The goal is to be more consistent and systematic about what is collected in schools, when it is collected, how it is collected, and how it is transmitted to Central Services. The provincial government has increased the types and kinds of information it needs for accountability purposes, and initially these requests were being sent to principals many times a year, often on very short notice and with little turnaround time. Accuracy and consistency were both victims in this paper process. Therefore, the jurisdiction compiled lists of all the different kinds of information required and translated these into a series of forms in the workbook. This will allow compilation of information required by various stakeholders, from the Treasurer and the Superintendent to staff in Learning Services, without further requests to the school administrator. These data, which have to be collected by September $30^{\text {th }}$ each year, drive the amount of funding each school receives and hence principals need to know how to obtain and collate these data. They include student enrolment and achievement data, data required for dollar-driven programs, and budget information.

One impact of the use of ICT is that the district has been able to do a better assessment of students' academic achievement as measured by the provincial tests. Based on the data, the district has been able to compare potential versus actual student outcomes, and identify poorly performing schools. However, at the district level, administrators were not sure of the extent to which principals were using the workbook's data gathering capability to collect information to support their school's goals.

The district uses the email system for most communication. All senior administrators are accessible electronically, which is not necessarily the case concerning telephone and face-to-face meetings. The email system is used to send out agendas and provide current information. The superintendent makes a formal visit to each school once a year. In addition, he meets with all principals once a month. The remainder of his work with his administrators is through e-mail.

In schools that have LANs, most principals have adopted the same procedures with their staff. It is a more efficient way to ensure that staff meeting agendas and weekly or daily bulletins are sent to all staff. Similarly, teachers can use it to correspond with each other about instructional topics as well as administrative matters. Some schools are beginning to receive correspondence from parents via e-mail and others have set up web pages with electronic portfolios which parents can access to view their children's work in the classroom. 
The principals all used e-mail for correspondence and had a variety of databases available. Those with an interest in ICT used it for communications with staff such as weekly news bulletins and e-mails and encouraged staff to use it for communication and instructional purposes. They did their own keyboarding and saw ICT as a learning resource. Those who were beginning users tended to focus on the administrative aspects of data-dissemination. For the majority there was a growing recognition of the potential of the medium and some had added or configured databases for their own school matters. They were pleased at their extent of involvement and access to timely information on district matters although their level of knowledge of the MIS databases varied. In some cases, the quality of the school infrastructure had limited staff use. Most schools had web sites and the majority saw these as an information and publicity source only while others used theirs for communication with parents and sharing learning resources with students.

While the district has implemented minimum technology standards, it recognizes that it does not yet have clear plans for implementing them with experienced principals who are not technology literate. They recognize this as a period of evolution, they know where they want to go, and are anxious to ensure that in achieving this goal neither the principals' motivation nor their other goals concerning the role of the principal in instruction suffer.

\section{CONCLUSION}

Although this jurisdiction is only beginning a process of technology integration, the impact of ICT has already been felt in the principals' offices. They are required to be more knowledgeable about various computer applications, to correspond easily via e-mail, and to organize and retrieve information. Some are finding that parents use e-mail to correspond with them. Already the district has used the information provided by schools to identify poorly performing schools and so there is increased pressure on them to ensure the quality of their own schools. Some schools have begun to do their own analyses but most are still at the information gathering and communication stages. Visscher \& Bloemen (1999) identified training as an important concern. This was true for the principals in this study, many of whom were learning on the job and did not feel they could wait for a districtwide initiative. As LANs become ubiquitous and all teachers have access to computers, then greater transparency, increased interaction, and reduced autonomy will continue to influence and change the work of educators. 


\section{REFERENCES}

Caldwell, B. \& Spinks, J. (1992). Leading the self-managing school. Falmer, London.

Bober, M.J. (2001). School information systems and their effects on school operations and culture. Journal of Research on Technology in Education, 33(5), Summer. [http://www.iste.org/jrte/33/5/bober.html] 09.05.2002.

Gurr, D. (2001). Principals, technology, and change. The Technology Source, September/October.[http://horizon.unc.edu/TS/default.asp?show+article\&id=867] 09.05.2002.

Haughey, M. (2002). Canadian research on ICTs. Paper presented at the Council of Ministers of Education PCERA Symposium, Information Technology and Learning, Montreal, April 30 - May 1. [http://www.cmec.ca/stats/pcera/RSEvents02/main_en.htm] 09.05.2002.

Telem, M. (1996). MIS implementation in schools: A systems socio-technical framework. Computers \& Education, 27(2), pp. 85-93.

Telem, M. (1997) The school computer administrator's (new) role impact on instruction administration in a high school: A case study. Computers \& Education, 28(4), pp. 213221.

Telem, M. (1999). A case study of the impact of school administration computerization on the department head's role. Journal of Research on Computing in Education, 31(4), pp. 385401.

Valenza, J.K. (1999). The principal who leads on technology is one who learns. School crossings. [http://crossings.phillynews.com/archive/k12/principal319.htm] 09.05.2002.

Visscher, A.J. \& Bloemen, P.P.M. (1999). Evaluation and use of computer-assisted management systems in Dutch schools. Journal of Research on Computing in Education, 32(1), pp.172-188.

Visscher, A.J. \& Fung, A.C.W. (2002). Lessons from implementing computerised school information systems in Hong Kong, the Netherlands and England. Paper presented at the ITEM 2002 conference, Helsinki, Finland. August 19-22.

Visscher, A.J., Wild, P. \& Fung, A. (Eds.) (2001). Information technology in educational management: Synthesis of experience, research and future perspectives in computerassisted school information systems. Kluwer, London..

Yeagley, R. (2001). Data in your hands. AASA School Administrator. (web edition). [http://www.aasa.org/publications/sa/2001_04/yeagley.htm] 09.05.2002. 